\title{
Laboratory Investigation on Physical, Rheological Thermal and Microscopic Characteristics of Water-Foamed Asphalt under Three Environmental Conditions
}

\author{
Wei Guo ${ }^{1}{ }^{1}$, Xuedong Guo ${ }^{1}$, Yingsong $\mathrm{Li}^{2}$ and Wenting Dai ${ }^{1, *(1)}$ \\ 1 School of Transportation, Jilin University, Changchun 130022, China; guowei17@mails.jlu.edu.cn (W.G.); \\ guoxd@jlu.edu.cn (X.G.) \\ 2 School of Transportation, Changchun College of Architecture, Changchun 130604, China; \\ ysli16@mails.jlu.edu.cn \\ * Correspondence: daiwt@jlu.edu.cn
}

Received: 19 February 2020; Accepted: 2 March 2020; Published: 4 March 2020

\begin{abstract}
Applications of water-foamed binders have received widespread attention due to its environmental and economic benefits. This study aims to evaluate the properties of water-foamed asphalt under three environmental conditions (high-temperature evaporation, low-temperature frozen and the freeze-thaw cycle). Conventional physical properties tests, dynamic shear rheometer test (DSR), differential scanning calorimetry test (DSC) and scanning electron microscope test (SEM) are employed to assess the physical, rheological thermal and microscopic characteristics of samples. Conventional physical properties test results showed that the performance of a foamed binder had declined under three environmental processes and the foamed asphalt gradually returned to the characteristics before being foamed, with the increase of process time. A comprehensive evaluation index, deterioration degree was proposed based on the test results and entropy theory, and the deterioration process of the foamed binder under three environmental conditions was quantified. Moreover, freeze-thaw (F-T) cycles had been proved to have the most significant influence on the performance of a foamed binder among three environmental factors, which was a key issue that limits the application and promotion of foamed asphalt in seasonal frozen regions. The DSR test showed that the resistance to high-temperature permanent deformation of the foamed binder was improved after F-T cycles, and the fatigue resistance became worse. The sensitivity analysis of complex modulus and frequency illustrated that foamed asphalt after F-T cycles were more sensitive to the loading frequency and less sensitive to the temperature. The DSC test indicated that the thermal stability of foamed asphalt was improved after F-T cycles. The disappearance of circular "cavitation" observed through SEM test revealed that moisture of foamed asphalt was gradually precipitated and self-healing phenomenon occurred during F-T cycles.
\end{abstract}

Keywords: water-foamed asphalt; properties evaluation; deterioration characteristic; entropy theory; factors analysis

\section{Introduction}

Asphalt pavement is the most widely used advanced pavement in global pavement construction due to the special properties such as low noise, high comfort and strong repairability [1-3]. More than $94 \%$ of the 2.7 million miles of paved roads in the United States are surfaced with asphalt $[4,5]$. In terms of existing asphalt pavement construction technology, hot mix asphalt (HMA) is a main technology [6-8]. During the production of hot mix asphalt, a large amount of fuel was consumed, 
and the massive toxic gases and dust was released $[9,10]$. These toxic gases would pollute the entire environment and seriously endanger human health [11,12].

Hence, shifting pavement engineering toward a more environment-friendly and sustainability industry has brought increased attention [13-16]. Warm mix asphalt (WMA) technology, as recent innovations in pavement engineering technology, has been appreciated $[17,18]$. The WMA technology can reduce the mixing and compaction temperature of the mixture by approximately $10-40{ }^{\circ} \mathrm{C}$ compared with HMA technology $[19,20]$. These lower production temperatures can yield numerous benefits, such as fewer environmental impacts, reduced cost, faster rehabilitation times and shorter traffic delays [21-24]. Organic additives, evotherm technology and foaming technology were the three main WMA technologies [25]. Common organic additives include Asphaltan-B, EC-120, Sasobit, etc. It can be incorporated into asphalt binder or directly into mixing pot. The organic additives can reduce production temperature, enhance rutting resistance and compactness of asphalt mixture [26]. Evotherm technology refers to the incorporation of surfactant and water during the mixing process of asphalt binder and aggregate. During mixing, the lipophilic group of the surfactant is compatible with the asphalt, and the moisture quickly vaporizes when exposed to high temperature, forming an adsorption moisture film with a lubricating function inside the asphalt, which changing the viscosity of asphalt, thereby achieving the ideal mixing temperature [27]. Among the above three WMA technical methods, foaming technology is the most common. According to the statistics, over 30 different WMA technologies were used in the US, while almost $60 \%$ of the technologies are based on the foaming method [28].

In general, the foaming technologies including water-bearing additive and water-based processes, especially the water-foaming processes do not require any costly additives to be added to the mixtures, and the foamed asphalt is produced with water injection into hot asphalt binder [29-32]. The viscosity of asphalt decreases significantly after the foaming process, and it can be mixed with aggregates at relatively low temperature [33,34]. Moreover, the foaming process increases the volume of asphalt binder with a large surface area in the unit volume leading to strong coating with high shear strength of the mix of foamed asphalt binder and aggregate. The preparation and application of water-foamed asphalt have been increasingly performed by researchers and practitioners $[35,36]$. Plenty of studies indicated that the quality of water-foamed asphalt could be measured by two indicators, namely the expansion ratio (ER) and half-life (HL), which is determined by water content and mixing temperature [37]. Arega et al. quantified the expansion and decay of foamed asphalt through laser and ultrasonic distance-measuring tools. Results indicated that higher water contents were associated with higher ER value but also faster rates of collapse [12]. In recent years, the research of water-foamed asphalt is mainly focused on performance evaluation, especially, the deterioration issue. Dong et al. assessed the influence of base asphalt aging levels on the foaming characteristics and rheological properties of foamed asphalt. The results showed that the deeper aging degree of asphalt for the foaming process needed higher temperatures and more foaming water content [38]. Punith et al. investigated the influence of long-term aging on moisture susceptibility of the foamed WMA mixture. It was reported that the long-term aging improved the moisture resistance of the WMA mixtures [39]. Abu Qtaish et al. evaluated the influence of aging on the micromechanical and chemical properties of foamed WMA and HMA. The conclusion showed that the WMA binders would experience equal or less aging over the service life of a pavement structure as compared to HMA binders [40].

In summary, although quite a lot studies that deal with the deterioration issue of water-foamed asphalt have been performed by researchers, whereas only a very few studies have been conducted on the properties of foamed asphalt under multiple deteriorating environments. At present, the research on asphalt deterioration issue generally focuses on thermal oxidative aging, also including water-foamed asphalt. However, the physical form of residual moisture in foamed asphalt is greatly affected by temperature, which inevitably causes the deterioration issue of water-foamed asphalt to have a significant connection with temperature environment (high-temperature evaporation, low-temperature frozen and freeze-thaw cycle). Thus, this study aims to evaluate the physical, rheological, thermal 
and microscopic characteristics of water-foamed asphalt under three environmental conditions (high-temperature evaporation, low-temperature frozen and freeze-thaw cycle) and judges the most significant environmental factors that affecting the properties of foamed asphalt. At the beginning of the experimental work of this study, both base asphalt and prepared water-foamed asphalt were treated with a high-temperature evaporation procedure, low-temperature frozen procedure and freeze-thaw (F-T) cycles procedure. The damaged samples were collected for the conventional physical properties tests (softening point, ductility and penetration rotational viscosity test), dynamic shear rheometer test (DSR) and differential scanning calorimetry test (DSC) to evaluate the properties of foamed asphalt under three environmental conditions. Moreover, the microscopic characteristics of the used asphalt samples were analyzed by using direct microstructure observations (SEM test). The technical route of this article is shown in Figure 1.

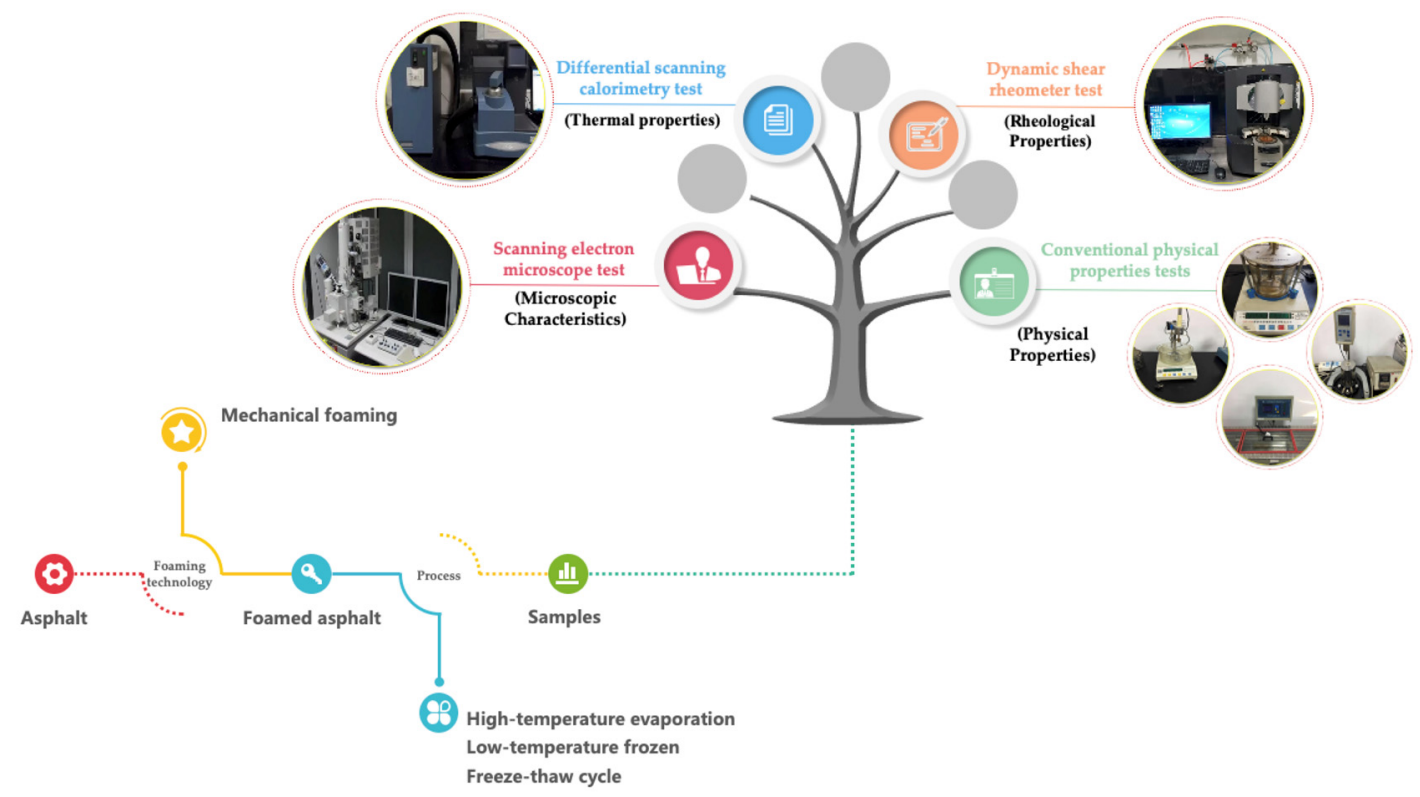

Figure 1. Technical route of this article.

\section{Materials}

\subsection{Bitumen}

A paving binder, 70\# asphalt (referred to as 70\#), widely used in highways, high-grade pavement and heavy-traffic asphalt pavement of China, were evaluated in this study. The 70\# asphalt with a 60/80 penetration grade produced was acquired from Qilu Branch of Sinopec Corp. (Qingdao, China) The technical parameters of 70\# asphalt are listed in Table 1.

Table 1. Technical parameters of 70\# asphalt.

\begin{tabular}{ccccccc}
\hline $\begin{array}{c}\text { Technical } \\
\text { Parameters }\end{array}$ & $\begin{array}{c}\mathbf{2 5}{ }^{\circ} \mathbf{C} \\
\text { Penetration }\end{array}$ & $\begin{array}{c}\mathbf{1 5}{ }^{\circ} \mathbf{C} \\
\text { Ductility }\end{array}$ & $\begin{array}{c}\text { Softening } \\
\text { Point }\end{array}$ & $\begin{array}{c}\text { Wax } \\
\text { Content }\end{array}$ & $\begin{array}{c}\text { Flash } \\
\text { Point }\end{array}$ & Density \\
\hline Units & $\mathrm{mm}$ & $\mathrm{cm}$ & ${ }^{\circ} \mathrm{C}$ & $\%$ & ${ }^{\circ} \mathrm{C}$ & $\mathrm{g} \cdot \mathrm{cm}^{-3}$ \\
$70 \#$ & 67.6 & $>100$ & 52.1 & 1.5 & 287 & 1.003 \\
Test procedure & $\mathrm{T} 0606$ & $\mathrm{~T} 0605$ & $\mathrm{~T} 0606$ & $\mathrm{~T} 0615$ & $\mathrm{~T} 0611$ & $\mathrm{~T} 0603$ \\
\hline
\end{tabular}

\subsection{Preparation of Water-Foamed Asphalt}

In this study, a foamed asphalt specimen was produced using a self-designed laboratory foaming machine as illustrated in Figure 2, where water was injected into the hot asphalt. The laboratory 
foaming machine consists of an electric shear meter, a smart magnetic heating sleeve, a high-length electric stirring rod and a cylindrical glass cup.

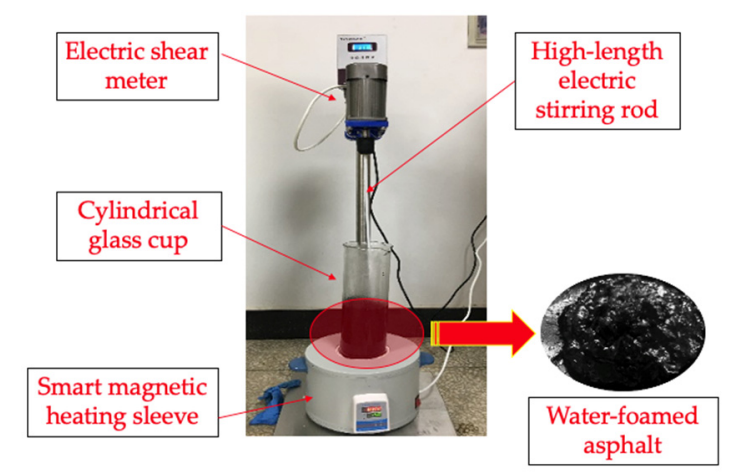

Figure 2. Self-designed laboratory foaming machine.

In the preparation process, the foaming temperature, water content and shearing rate exhibited a significant influence on foaming quality of asphalt. In order to obtain the high-quality foamed asphalt, various foamed asphalt samples were evaluated at a variety of foaming temperature $(150,160,170$ and $\left.180{ }^{\circ} \mathrm{C}\right)$, water content weight of asphalt $(1 \%, 2 \%, 3 \%$ and $4 \%)$ and shearing rate $(500,1000$ and $1500 \mathrm{r} / \mathrm{min}$ ) in this study. There are several foaming parameters: ER, HL, foaming index and rate of collapse of semi-stable bubbles for foaming characterization. These parameters and measuring techniques are described in the past study [41-44]. In this paper, the ER and HL index was employed to optimize the foaming process of 70\# asphalt based on the response surface methodology (RSM). ER is the ratio between the max foamed asphalt and non-foamed asphalt by volume. It is a reflection of the volume expanding of asphalt and a greater expanding means a better mixing process with aggregates. HL is the fall time of foamed asphalt from the maximum volume to half of that. It is a reflection of the stability of foamed asphalt, and the longer half-life could improve the quality of foamed asphalt mixtures.

The test results showed that for the 70\# asphalt, when the foaming temperature is $159{ }^{\circ} \mathrm{C}$, water content is $2.1 \%$, the shearing rate is $1156 \mathrm{r} / \mathrm{min}$, the foaming quality is the best, the expansion rate is 13.9 and the half-life is $11.2 \mathrm{~s}$.

\section{Characterization and Performance Testing}

\subsection{Three environmental Conditions Procedure}

Asphalt binder is a complex viscoelastic material, which bonds the aggregates together and fills the pores between the aggregates, so that the mixture acquired a certain strength and deformation resistance [44-47]. Although the proportion of asphalt in the mixture is about 5\%, the high- and low-temperature properties, moisture susceptibility and durability of the asphalt pavement are closely related to the properties of the asphalt binder. Traditional hot mix asphalt has high construction temperature, high energy consumption and emission of harmful gases. However, the application of warm mix asphalt technology has effectively solved this problem, and the foamed warm asphalt prepared by the water foaming technology has more technical and economic advantages. At present, water-foamed asphalt has been widely used in the warm climate of the south, but there are few studies and applications of water-foamed asphalt in the seasonally frozen region. In the foaming process, moisture vapor diffuses into the asphalt continuum. After the foam bursts, the residual moisture in the water-foamed asphalt is not completely dissipated. In the severe and harsh environment of the seasonally frozen region, the residual moisture has a direct impact on the physicochemical properties and rheological properties of asphalt pavement. Taking Changchun City as an example, in the seasonally frozen region, the pavement temperature in July is as high as $56{ }^{\circ} \mathrm{C}$, the pavement 
temperature in February is $-36^{\circ} \mathrm{C}$ and the pavement temperature difference between day and night in March is as high as $25^{\circ} \mathrm{C}$. The extreme environment calls for more stringent requirements for the properties of water-foamed asphalt binder. In this study, high-temperature evaporation procedure, low-temperature frozen procedure and freeze-thaw cycle procedure were designed to simulate the extreme weather for evaluating the application of water-foamed asphalt in the seasonally frozen region.

\subsubsection{High-Temperature Evaporation Procedure}

In summer, an asphalt binder transforms into a flow state with the increase of temperature, and gradually loses the supporting and stabilizing effect on the skeleton structure, causing the original skeleton structure to be destroyed, the asphalt mortar flowing to the side and the asphalt mixture on both sides of the wheel track rising, and eventually a corrugated rut is formed. In order to assess the deteriorating performance of water-foamed asphalt under a high-temperature environment, a high-temperature evaporation procedure was designed and the procedure mainly consists of two steps.

Step 1: According to the optimum foaming process, 70\# water-foamed asphalt samples were prepared with a fixed-size plate to ensure the dimensions of asphalt samples is approximately $5 \mathrm{~mm} \times$ $250 \mathrm{~mm} \times 250 \mathrm{~mm}$.

Step 2: the water-foamed asphalt samples were placed in the oven at $60{ }^{\circ} \mathrm{C}$ for $4 \mathrm{~h}$. The test temperature, $60^{\circ} \mathrm{C}$, is mainly referred to the test temperature of the standard Marshall test and the rutting test, and the heating time of $4 \mathrm{~h}$ refers to the high-temperature period of the pavement from 10 am to 3 pm in summer.

As described above, a complete high-temperature evaporation cycle was completed. Then, after $1,2,3,5,10,20$ and 30 high-temperature evaporation cycles, damaged samples were collected for physicochemical property tests to explore the deteriorating performance of water-foamed asphalt under a high-temperature environment.

\subsubsection{Low-Temperature Frozen Procedure}

Low-temperature cracking is one of the main damage forms of asphalt pavement, especially, in the seasonal frozen region and severe cold region. As the ambient temperature decreases, the elasticity of asphalt increases, the flexibility disappears and becomes brittle and asphalt binder is easily cracked under the load, thereby reducing the service life and quality of the pavement surface. In this study, a low-temperature frozen procedure was designed to evaluate the deteriorating performance of water-foamed asphalt under a frozen environment, and the low-temperature frozen procedure mainly consists of two steps.

Step 1: According to the optimum foaming process, 70\# water-foamed asphalt samples were prepared with a fix-size plate to ensure the dimensions of asphalt samples is approximately $5 \mathrm{~mm} \times$ $250 \mathrm{~mm} \times 250 \mathrm{~mm}$.

Step 2: the water-foamed asphalt samples were placed in the precision temp-enclosure at $-20{ }^{\circ} \mathrm{C}$ and frozen for $24 \mathrm{~h}$.

As per the method described above, a complete low-temperature frozen cycle was completed. Then, after 1, 2, 3, 5, 10, 20 and 30 low-temperature frozen cycles, damaged samples were collected for physicochemical property tests to explore the deteriorating performance of water-foamed asphalt under a frozen environment.

\subsubsection{Freeze-Thaw Cycle Procedure}

In frozen regions, freeze-thaw (F-T) damage is the main type of pavement damage, causing a variety of poor conditions in the asphalt pavement, such as cracks, pits, potholes and slush. These conditions shorten the service life of asphalt pavement, increase the maintenance frequency and costs and affect the smooth flow of traffic and transportation safety. In this study, an F-T procedure was 
designed to explore the deteriorating performance of water-foamed asphalt under the F-T environment, and the F-T procedure mainly consists of three steps.

Step 1: According to the optimum foaming process, 70\# water-foamed asphalt samples were prepared with a fix-size plate to ensure the dimensions of asphalt samples is approximately $5 \mathrm{~mm} \times$ $250 \mathrm{~mm} \times 250 \mathrm{~mm}$.

Step 2: $0.2 \mathrm{~g} / \mathrm{mL} \mathrm{CaCl}_{2}$ solution was prepared, and the water-foamed asphalt ware submerged in a container containing $\mathrm{CaCl}_{2}$ solution, the container with specimens were placed in the precision tem-enclosure at $-15^{\circ} \mathrm{C}$ and frozen for $10 \mathrm{~h}$.

Step 3: The samples with container were melted at $15{ }^{\circ} \mathrm{C}$ for $16 \mathrm{~h}$ through adjusting the temperature controller.

As per the method described above, a complete F-T cycle was completed [48]. Then, after 1, 2, 3, 5, 10, 20 and $30 \mathrm{~F}-\mathrm{T}$ cycles, damaged samples were collected for physicochemical property test to explore the deteriorating performance of water-foamed asphalt under the freeze-thaw cycle environment.

\subsection{Asphalt Binder Test Methods}

In this study, the properties of water-foamed asphalt under three different environments were characterized through conventional physical properties tests, DSR test, DSC test and SEM test for a better understanding of the workability of water-foamed asphalt under different environments. The conventional physical properties tests were employed to characterize the deterioration of water-foamed asphalt under different environmental factors and determine the most significant environmental factors for foamed asphalt. The DSR test was conducted to assess the high-temperature stability and fatigue resistance of treated foamed asphalt. The DSC test was conducted to evaluate thermal properties of water-foamed asphalt under the most adverse environmental factor. The SEM test was employed for microscopic observation of water-foamed asphalt samples.

\subsubsection{Conventional Physical Properties Test}

The conventional physical properties tests on water-foamed asphalt samples under different conditions such as the softening point, ductility and penetration were performed according to ASTM standards D5, D36 and D113 [49-51], respectively. Moreover, the rotational viscosity test was performed through a Brookfield rotational viscometer. The intercept $(K)$ along with slope $(A)$ were obtained to calculate the penetration index $(\mathrm{PI})$ through linearly regressing the logarithm of penetration $(P)$ against temperature $(T)$.

$$
\mathrm{PI}=\frac{30}{1+50 A}-10
$$

\subsubsection{Dynamic Shear Rheometer Test (DSR)}

DSR test is a general-purpose instrument for testing and evaluating the rheological properties of polymer compounds, and it can be employed to assess the high-temperature stability and fatigue resistance of asphalt [52]. Two test parameters, complex shear modulus $\left(G^{*}\right)$ and the phase $(\delta)$ can be obtained from the DSR test, to characterize the viscoelastic properties. $G^{*}$ is defined as the total resistance of the asphalt during repeated shear deformation, and it consists of two parts, the elastic part $\left(G^{\prime}\right)$ and the viscous part $\left(G^{\prime \prime}\right)$. The index $G^{\prime}\left(G^{\prime}=G^{*} \times \cos \delta\right)$ is the storage shear modulus (elastic modulus), which reflects the storage and release of energy during the deformation of the asphalt. The index $G^{\prime \prime}\left(G^{\prime \prime}=G^{*} \times \sin \delta\right)$ is the loss shear modulus (viscosity modulus), which reflects the lost energy during the deformation of the asphalt. The smaller the $G^{\prime \prime}$ value, the stronger the fatigue resistance of asphalt. The index $\delta$ is an index to characterize the elastic and viscous deformation. The larger $\delta$ value, the closer the material is to the viscous body. $G^{*} / \sin \delta$ is defined as an index of rutting factor, which characterize the deformation resistance of asphalt. The smaller the $G^{*} / \sin \delta$ value, the worse the deformation resistance of asphalt pavement. The asphalt binder specification of SHRP (Strategic Highway Research Program) stipulates that the rutting factor of base asphalt should meet the 
requirements, $G^{*} / \sin \delta \geq 1.0 \mathrm{KPa}$. The AR1500ex shear rheometer produced by the TA company (Boston, MA, USA) was employed to characterize the rheological properties of water-foamed asphalt through the temperature sweep test and frequency sweep test. Temperature sweep tests were conducted on water-foamed samples under the control deformation mode at a strain equal to $12 \%$ and frequency equal to $1.59 \mathrm{~Hz}$. This frequency of oscillation can simulate the shear stress corresponding to a traffic speed of approximately $100 \mathrm{~km} / \mathrm{hr}$. Complex shear modulus $\left(G^{*}\right)$ and phase angle $(\delta)$ were measured at temperatures ranging from 52 to $76^{\circ} \mathrm{C}$ at $2{ }^{\circ} \mathrm{C}$ increments for water-foamed asphalt. The diameter of the asphalt sample fixture was $25 \mathrm{~mm}$, while the test spacing of asphalt sample was $1 \mathrm{~mm}$. In a frequency sweep test, the frequency ranged from 0.1 to $100 \mathrm{rad} / \mathrm{s}$ and these tests were conducted at $52{ }^{\circ} \mathrm{C}$ due to the average pavement temperature in summer. The parallel plates with a diameter of $25 \mathrm{~mm}$ and a gap of $1 \mathrm{~mm}$ were selected for the tests. From all of the two tests, the linear viscoelastic parameters such as $G^{*}$ (complex shear modulus) and $\delta$ (phase angle) were obtained to characterize the rheological properties of the water-foamed asphalt binder.

\subsubsection{Differential Scanning Calorimetry Test (DSC)}

The differential scanning calorimetry test of foamed asphalt was carried out through a 2910 differential scanning calorimeter produced by the TA company of the United States. The range of the testing temperature was from -80 to $200{ }^{\circ} \mathrm{C}$, and the heating rate was $10^{\circ} \mathrm{C} / \mathrm{min}$ under a nitrogen atmosphere. The DSC curve is the heat flow rate as the ordinate and the temperature is the abscissa. The difference between the curve and the baseline indicates the heat absorption rate of the sample. The convex peak in the curve indicates the endothermic reaction, and the concave valley is an exothermic reaction. The size of the peak area formed by the curve peak and the baseline reflects the change of heart, which is defined as the Enthalpy changes $(\Delta H)$. The $\Delta H$ value of asphalt in a certain temperature range is large, indicating that the thermal storage stability of the materials is poor in this temperature range. Thus, the thermal properties of asphalt can be evaluated through the peak area, location and number of DSC curve. In general, the flatter the DSC curve, the less or no endothermic peak of the asphalt, and the asphalt has better thermal stability. The higher the endothermic peak, the greater the number of constituents that the agglomerated state has changed in asphalt. The wider the endothermic peak, the more kinds of constituents that the agglomerated state has changed in asphalt, and the greater the change in the physical properties of the asphalt.

\subsubsection{Scanning Electron Microscope Test (SEM)}

SIGMA 300 scanning electron microscope produced by the Carle Carl Zeiss Company (Obercohen, Germany) was employed for microscopic observation of water-foamed asphalt samples. The working principle is to scan the foamed asphalt with a very fine electron beam. The secondary electrons excited from the electron beam are collected by the detector and converted into an optical signal by a scintillator, which is then converted into an electrical signal by an amplifier and a photomultiplier tube. Thus, a scanned image synchronized with the electron beam is displayed. The distribution of residual moisture in foamed asphalt and the interface contact between residual moisture and asphalt can be seen through the SEM test.

\section{Results and Discussion}

\subsection{Physical Properties}

\subsubsection{The influence of High-Temperature Evaporation on Physical Properties}

The penetration test results of samples with high-temperature evaporation cycles are shown in Figure 3. 


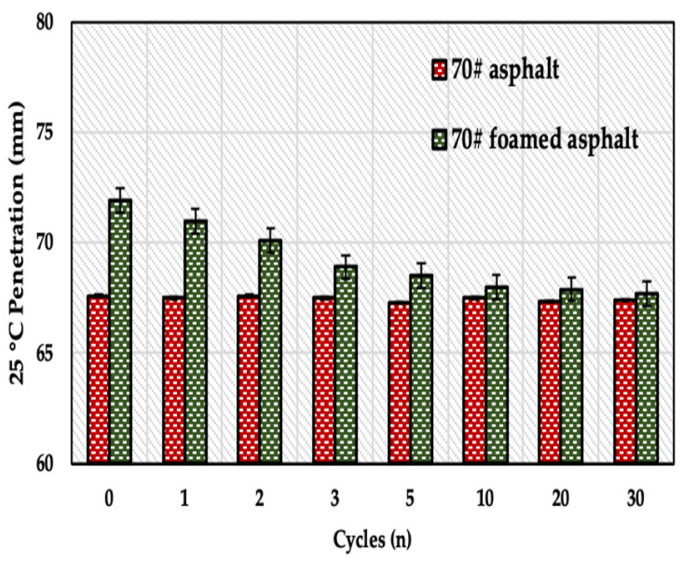

(a)

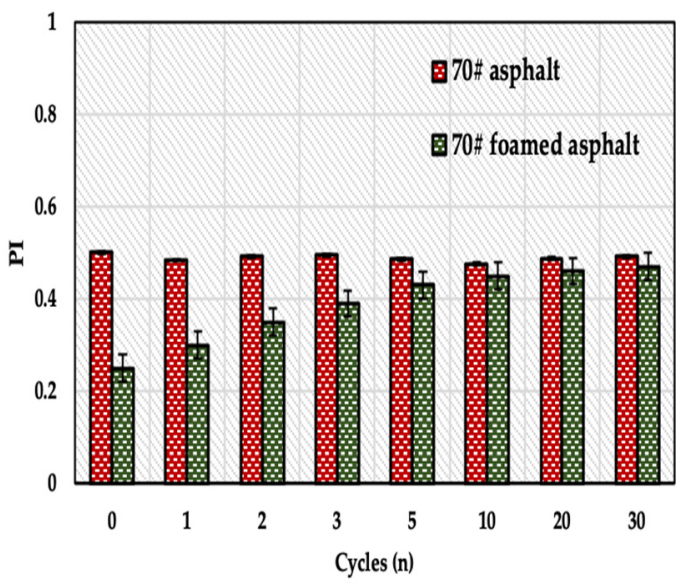

(b)

Figure 3. Penetration test results of samples with high-temperature evaporation cycles: (a) $25{ }^{\circ} \mathrm{C}$ penetration and (b) penetration index.

It can be seen from Figure 3 that the penetration of 70\# foamed asphalt decreased rapidly with the increase of the cycles. At 30 cycles, the penetration of foamed asphalt decreased by $5.84 \%$. However, high-temperature evaporation procedure had less influence on the penetration of base asphalt. There were two different changes in the penetration test results of foamed asphalt and base asphalt under the high-temperature evaporation procedure. The penetration of the base asphalt did not change significantly with the cycles. However, the penetration of foamed asphalt decreased rapidly with the increase of the cycles, and the penetration of 70\# foamed asphalt was very close to that of 70\# asphalt at 15 cycles, which indicates that most of the moisture remained in the asphalt had evaporated after 15 cycles. From Figure 3b, it can be summarized that the state of asphalt binder was extremely unstable after foaming, and the PI value foamed asphalt increased with the increase of the cycles due to the evaporation of moisture remaining in asphalt.

The softening point test results of samples with high-temperature evaporation cycles are shown in Figure 4.

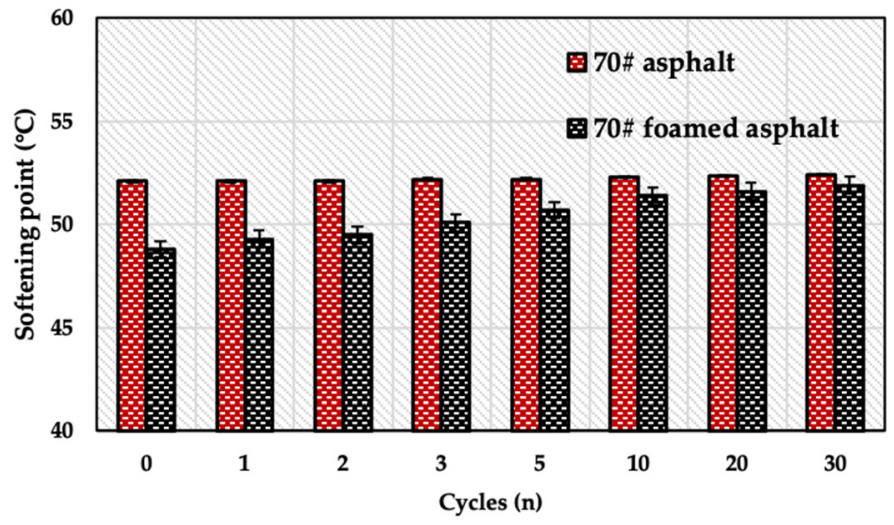

Figure 4. Softening point test results of samples with high-temperature evaporation cycles.

From Figure 4, the softening point test results of asphalt samples were consistent with the penetration test. The influence of high-temperature evaporation on base asphalt was not obvious, but the influence on the foamed asphalt was significant. The softening point of foamed asphalt gradually increased with the cycles, but was always smaller than the softening point of the base asphalt. The reason might be that some of the residual moisture was difficult to volatilize in a short 
time, which affected the high temperature stability of the foamed asphalt. However, as the number of cycles increased, the residual moisture gradually evaporated and the high temperature performance of foamed asphalt was gradually improved.

The ductility results of samples with high-temperature evaporation cycles are shown in Figure 5.

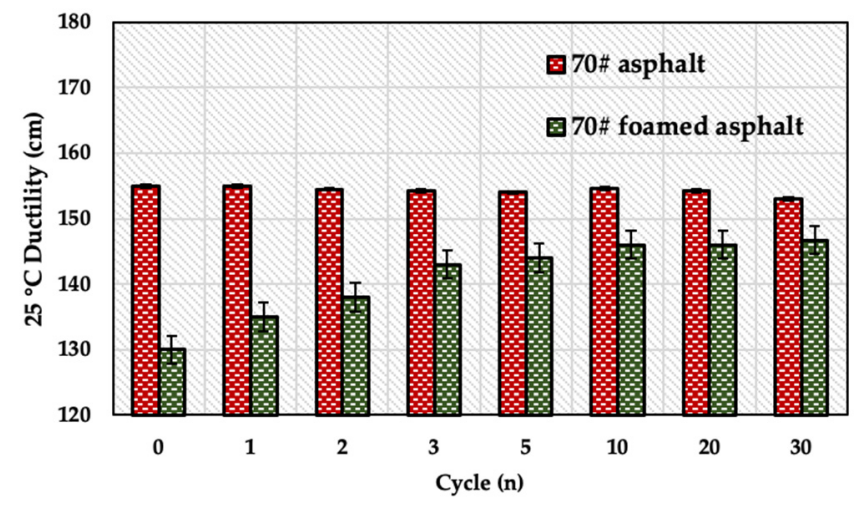

Figure 5. Ductility results of samples with high-temperature evaporation cycles.

It can be seen from Figure 5 that the ductility of foamed asphalt was smaller than that of base asphalt. This might be due to the existence of moisture, which had destroyed the homogeneity of asphalt. The ductility of foamed asphalt had improved after 30 cycles, but it had not recovered to the properties of base asphalt. It might be that the residual moisture that destroys the homogeneity of base asphalt is not completely volatilized. Moreover, the Internal "honeycomb" structure formed by the previous water vapor isolated the asphalt, reduced the joint area of the asphalt and destroyed the colloid structure of asphalt, which reduced the cross-section during the tensile process and reduced the ductility of the specimen. After 30 cycles, the ductility of $70 \#$ foamed asphalt still meets the requirements (ductility value of $70 \#$ asphalt $>100 \mathrm{~cm}$ ).

The rotational viscosity test results of samples with high-temperature evaporation cycles are shown in Figure 6.

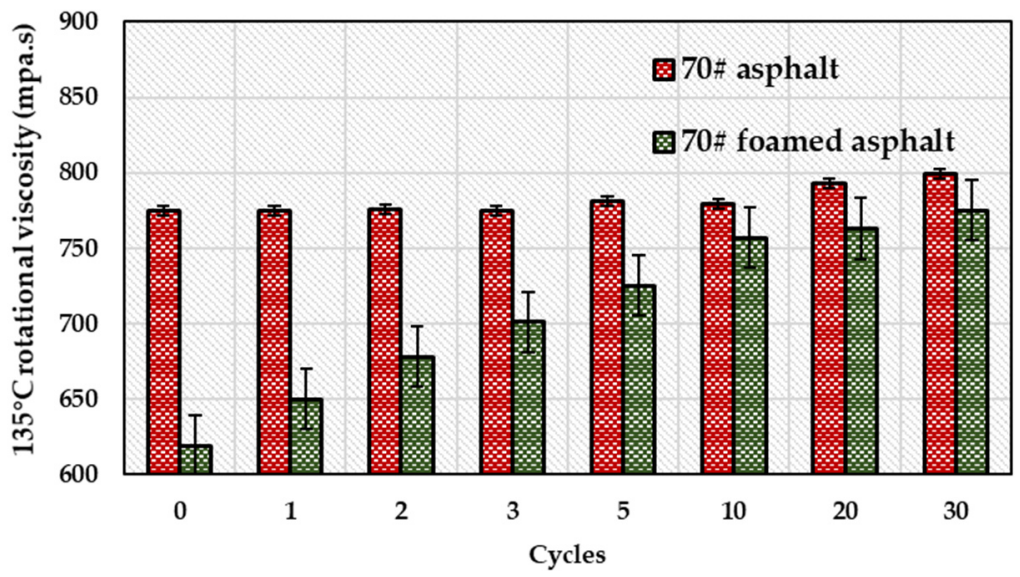

Figure $6.135^{\circ} \mathrm{C}$ rotational viscosity test results of samples with high-temperature evaporation cycles.

As can be seen from Figure 6, with the increase of high-temperature evaporation cycles, the rotational viscosity of 70\# foamed asphalt gradually increased rapidly and then entered a slow growth phase, which interpreters suggest that foamed asphalt should be mixed with aggregates quickly after production. Comparing with the other three evaluation indexes of penetration, ductility and the softening point, the influence of high-temperature evaporation procedure on the rotational viscosity of foamed asphalt was more obvious, which indicates that residual moisture content had a significant 
effect on the rotational viscosity of foamed asphalt. Due to the viscosity characteristics of foamed asphalt with times, the storage of foamed asphalt was still a challenge at present.

\subsubsection{The influence of Low-Temperature Frozen on Physical Properties}

The softening point, ductility, penetration test and rotational viscosity test results of samples with low-temperature frozen cycles are shown in Table 2.

Table 2. Conventional physical properties test results of foamed and non-foamed asphalt with low-temperature frozen cycles.

\begin{tabular}{|c|c|c|c|c|c|c|}
\hline Type & Cycles & $\begin{array}{c}25{ }^{\circ} \mathrm{C} \\
\text { Penetration } / \mathrm{mm}\end{array}$ & $\begin{array}{c}\text { PI } \\
\text { Value }\end{array}$ & $\begin{array}{l}\text { Softening } \\
\text { Point } /{ }^{\circ} \mathrm{C}\end{array}$ & $\begin{array}{c}135{ }^{\circ} \mathrm{C} \\
\text { Viscosity/mpa.s }\end{array}$ & $\begin{array}{c}25{ }^{\circ} \mathrm{C} \\
\text { Ductility/cm }\end{array}$ \\
\hline \multirow{8}{*}{ 70\# asphalt } & 0 & 67.6 & 0.5 & 52.1 & 775 & 155 \\
\hline & 1 & 66.8 & 0.5238 & 52.7 & 798 & 133 \\
\hline & 2 & 63.7 & 0.544 & 53.13 & 807 & 139.8 \\
\hline & 3 & 63.1 & 0.5437 & 53.88 & 812 & 128.3 \\
\hline & 5 & 60.7 & 0.5846 & 54.46 & 823 & 109.8 \\
\hline & 10 & 60.3 & 0.6033 & 55.4 & 846 & 95.9 \\
\hline & 20 & 59.4 & 0.6664 & 55.61 & 859 & 72.3 \\
\hline & 30 & 58.3 & 0.7053 & 55.8 & 889 & 54.7 \\
\hline \multirow{8}{*}{$\begin{array}{c}70 \# \\
\text { water-foamed } \\
\text { asphalt }\end{array}$} & 0 & 71.9 & 0.25 & 48.8 & 619 & 130 \\
\hline & 1 & 70.7 & 0.3705 & 49.12 & 634 & 118.5 \\
\hline & 2 & 69.6 & 0.4375 & 50.18 & 657 & 97.2 \\
\hline & 3 & 68.4 & 0.494 & 50.52 & 666 & 82.4 \\
\hline & 5 & 65.7 & 0.5414 & 51 & 689 & 618.8 \\
\hline & 10 & 64.3 & 0.5606 & 51.9 & 703 & 51.7 \\
\hline & 20 & 63.5 & 0.5954 & 52.5 & 719 & 34.3 \\
\hline & 30 & 63.1 & 0.619 & 52.6 & 724.2 & 29.2 \\
\hline
\end{tabular}

From Table 2, the test results showed that low-temperature frozen had a significant influence on the properties of the base or foamed asphalt. The penetration of asphalt samples decreased with the increase of low-temperature frozen cycles. The penetration of 70\# asphalt and 70\# foamed asphalt decreased by $12.2 \%$ and $13.8 \%$, respectively. This is due to the aging of asphalt samples under the low-temperature frozen procedure, which increases the proportion of asphaltenes, enhances the interaction between the asphalt molecules, changes the colloidal structure of asphalt and hardens the asphalt material. The penetration of foamed asphalt is always greater than that of base asphalt under a low-temperature procedure. This indicates that the internal moisture volatilizes slowly at low temperatures, so that the high residual moisture content plays a significant role in effectively increasing the penetration of asphalt. The PI index showed that the temperature susceptibility of foamed asphalt is worse than the base asphalt under a low-temperature frozen procedure.

The softening point results showed that the softening point of two asphalt samples increased with the increase of low-temperature frozen cycles, which verified the aging phenomenon of asphalt asphalts under low-temperature frozen cycles. The trend of the softening point of asphalt before and after foaming is almost the same, and the softening point of 70\# asphalt and 70\# foamed asphalt increased by $7.1 \%$ and $7.2 \%$ after 30 frozen cycles. It may be that the moisture in the ice state has little influence on the high-temperature properties of asphalt, and the asphalt material is more susceptible to the low-temperature frozen procedure, which increases the softening point of asphalt and enhances the high-temperature stability.

The viscosity results showed that the influence of low-temperature frozen procedure on the viscosity of asphalt is more significant than that of high-temperature evaporation procedure, but the opposite is true for the foamed asphalt. Moreover, it was found that there were more bubbles that emerged during the rotational viscosity test of frozen foamed asphalt. This indicates that low-temperature has a significant influence on the viscosity of asphalt material, but the moisture remaining in foamed asphalt can effectively reduce the adverse effect, which may be due to less moisture precipitation of foamed asphalt under a frozen procedure. This also indicates that the 
transportation and placement of foamed asphalt should be carried out under low temperature, so that the viscosity of foamed asphalt can be preserved as much as possible. The viscosity of foamed asphalt increased by $25.2 \%$ and $17 \%$ after 30 evaporation cycles and 30 frozen cycles, respectively. This indicates that the viscosity increase of foamed asphalt is due to the low-temperature aging under low temperature, and the viscosity increase of foamed asphalt is due to the evaporation of moisture under high temperature.

The ductility results illustrated that the ductility of asphalt samples is gradually reduced with the prolongation of the frozen procedure, and the ductility of the base asphalt is always greater than foamed asphalt. After 30 frozen cycles, the ductility of base asphalt and foamed asphalt decreased by $64.7 \%$ and $77.6 \%$, respectively. It very likely that the colloid structure of foamed asphalt is affected by the internal moisture. The internal moisture becomes an ice crystal when the temperature is lower than the freezing point, the volume of internal moisture expands and the temperature stress is generated at the interface of two phases. When the temperature stress accumulates enough, the continuity of asphalt material will be destroyed.

\subsubsection{The Influence of F-T Cycle on Physical Properties}

The softening point, ductility, penetration test and rotational viscosity test results of samples with F-T cycles are shown in Table 3.

Table 3. Conventional physical properties test results of foamed and non-foamed asphalt with freeze-thaw $(\mathrm{F}-\mathrm{T})$ cycles.

\begin{tabular}{|c|c|c|c|c|c|c|}
\hline Type & Cycles & $\begin{array}{c}25{ }^{\circ} \mathrm{C} \\
\text { Penetration } / \mathrm{mm}\end{array}$ & $\begin{array}{c}\text { PI } \\
\text { Value }\end{array}$ & $\begin{array}{c}\text { Softening } \\
\text { Point } /{ }^{\circ} \mathrm{C}\end{array}$ & $\begin{array}{c}135^{\circ} \mathrm{C} \\
\text { Viscosity/mpa.s }\end{array}$ & $\begin{array}{c}25^{\circ} \mathrm{C} \\
\text { Ductility/cm }\end{array}$ \\
\hline \multirow{6}{*}{ 70\# asphalt } & 0 & 67.6 & 0.5 & 52.1 & 775 & 155 \\
\hline & 2 & 55.37 & 0.584 & 53.3 & 823 & 92 \\
\hline & 3 & 53.08 & 0.593 & 54 & 859 & 84 \\
\hline & 5 & 47.4 & 0.625 & 54.7 & 878 & 69.5 \\
\hline & 20 & 46.5 & 0.766 & 56.1 & 921 & 47.3 \\
\hline & 30 & 44.65 & 0.775 & 56.5 & 954.8 & 32.7 \\
\hline \multirow{4}{*}{$\begin{array}{c}70 \# \\
\text { water-foamed } \\
\text { asphalt }\end{array}$} & 0 & 71.9 & 0.25 & 48.8 & 619 & 130 \\
\hline & 1 & 63.27 & 0.35 & 50.3 & 689 & 108.5 \\
\hline & 2 & 60.9 & 0.475 & 51.4 & 779 & 87.2 \\
\hline & 30 & 43.67 & 0.769 & 57.2 & 1148 & 19.2 \\
\hline
\end{tabular}

From Table 3, the penetration of asphalt samples decreased with the increase of F-T cycles. The penetration of base asphalt and foamed asphalt decreased by $33.9 \%$ and $39.3 \%$ after $30 \mathrm{~F}-\mathrm{T}$ cycles. Moreover, the PI value of foamed asphalt was also lower than that of base asphalt after $30 \mathrm{~F}-\mathrm{T}$ cycles. This illustrates that the influence of F-T cycles on the properties of foamed asphalt was more obvious. Asphaltene has the ability to reduce the interfacial tension of asphalt-moisture. Polar groups such as hydroxyl, amino and carboxyl groups contained in the asphalt promote the movement of asphaltene molecules to the asphalt-moisture interface, and an asphalt film having a certain strength is formed at the interface. As the $\mathrm{F}-\mathrm{T}$ cycles procedure progresses, the hardening phenomenon caused by the complex molecular structure and self-association tendency of asphaltenes is also more obvious. Furthermore, the interaction of residual moisture, temperature and air accelerates the hardening phenomenon under F-T cycles, resulting in aging and deterioration of the asphalt and reducing the penetration of asphalt. The softening point of asphalt samples increased with the increase of F-T cycles. The softening point of base asphalt and foamed asphalt increased by $8.4 \%$ and $17.2 \%$ after $30 \mathrm{~F}-\mathrm{T}$ cycles, which indicates that F-T cycles have a more significant effect on the high-temperature 
performance of foamed asphalt compared with frozen cycles and evaporation cycles. The viscosity of asphalt increased with the increase of F-T cycles. The viscosity of base asphalt and foamed asphalt increased by $23.2 \%$ and $71.2 \%$ after $30 \mathrm{~F}-\mathrm{T}$ cycles, and the viscosity of foamed asphalt was larger than that of base asphalt after $30 \mathrm{~F}-\mathrm{T}$ cycles. Moreover, the greater number of F-T cycles, the less the bubbles generated during a rotational viscosity test. This may be due to a large amount of moisture released from foamed asphalt under F-T cycles. Moreover, in the environment of $\mathrm{CaCl}_{2}$ solution, the moisture molecules are prone to precipitate from foamed asphalt under the action of osmotic pressure, which accelerates the precipitation phenomenon of moisture. The ductility of asphalt samples decreased with the increase of F-T cycles. The ductility of base asphalt and foamed asphalt decreased by $78.9 \%$ and $85.2 \%$ after $30 \mathrm{~F}-\mathrm{T}$ cycles, which indicates $\mathrm{F}-\mathrm{T}$ cycles procedure is fatal to foamed asphalt.

In summary, for foamed asphalt, after 30 evaporation cycles, the penetration decreased by $5.8 \%$, the softening point increased by $6.4 \%$, the ductility decreased by $12.8 \%$ and the viscosity increased by $28.6 \%$. After 30 frozen cycles, the penetration decreased by $13.8 \%$, the softening point increased by $7.2 \%$, the ductility decreased by $77.6 \%$ and the viscosity increased by $12.5 \%$. After $30 \mathrm{~F}-\mathrm{T}$ cycles, the penetration decreased by $39.3 \%$, the softening point increased by $17.2 \%$, the ductility decreased by $85.2 \%$ and the viscosity increased by $71.2 \%$. Whether it is a high-temperature procedure, or low-temperature frozen procedure or F-T cycles procedure, the increase of the softening point and viscosity, the decrease of ductility and penetration of foamed asphalt, are inevitable. This is mainly due to the aging of asphalt and precipitation of moisture from foamed asphalt under environmental factors.

Only one indicator cannot fully evaluate the deterioration process of foamed asphalt under different environmental influences. Therefore, the entropy method was employed to seek an objective and effective comprehensive index, deterioration degree, containing penetration, softening point, ductility and viscosity indexes, for determining the deterioration state of foamed asphalt. The entropy method is a method derived from the entropy theory to weigh the importance of the research object. According to the information entropy theory, the role of an indicator in the measurement index system depends on the variation degree of the indicator. The variation degree of an indicator is directly proportional to the amount of information it reflects. The higher the variation degree, the greater the recognition effect. In other words, the smaller the entropy value of an indicator, the larger its variation coefficient and the greater its weight, so the more important the indicator is. According to the entropy theory, the deterioration degree of base and foamed asphalt with different environmental cycles is calculated, and the results are shown in Figure 7.

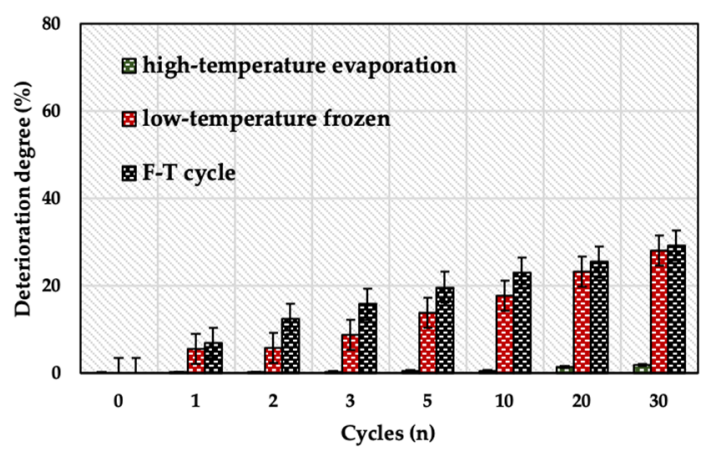

(a)

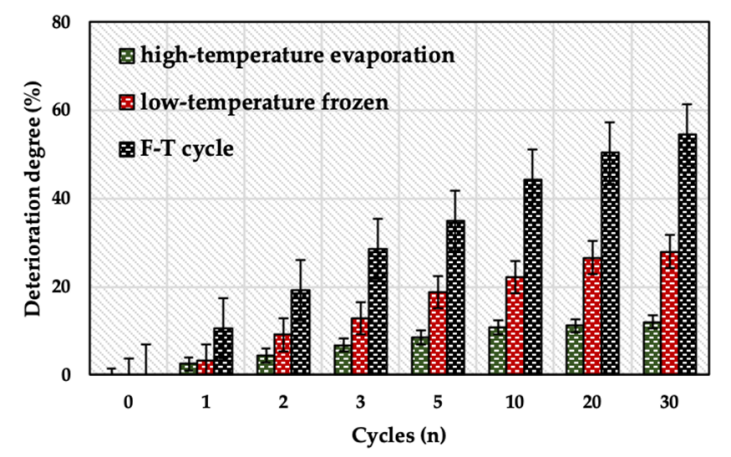

(b)

Figure 7. Deterioration degree of 70\# asphalt and 70\# foamed asphalt after with F-T cycles: (a) 70\# asphalt and (b) 70\# foamed asphalt.

From Figure 7, the deterioration degree of the base and foamed asphalt increase as the cycles increased, which indicates the properties of base and foamed asphalt becomes worse. In general, the deterioration degree of the foamed binder was greater than that of base asphalt under multiple environments. This may be due to the residual moisture in foamed asphalt, which destroys the 
homogeneity of the asphalt physically. This "partition" effect leads to poor stability of foamed asphalt under various environments. After 30 frozen cycles, the deterioration degree of the base and foamed asphalt is $28.05 \%$ and $27.96 \%$, respectively. This indicates that the deterioration process of foamed asphalt under the frozen condition is almost the same as that of base asphalt. It also reveals that the deterioration of foamed asphalt under a frozen environment is mainly related to the asphalt binder, and the residual moisture plays a very small role in it. The deterioration degree of foamed asphalt after 30 evaporation cycles, frozen cycles and F-T cycles is $12.03 \%, 27.96 \%$ and $54.62 \%$, respectively. This indicates F-T cycles has the most significant influence on the performance of foamed binder among three environmental factors, which is a key issue that limits the application and promotion of foamed asphalt in seasonal frozen regions.

\subsection{Thermal Properties}

Figure 8 presents the thermal properties of 70\# asphalt and 70\# foamed asphalt. It can be known from Figure 8 that the glass transition temperature of $70 \#$ asphalt and $70 \#$ foamed asphalt is $-29.77^{\circ} \mathrm{C}$ and $-15.88^{\circ} \mathrm{C}$, respectively. The value of glass transition temperature indicates the temperature below which the asphalt binder changes from viscoelastic state to the glassy state. The lower the glass transition temperature, the better the asphalt to resist low-temperature cracking. The test results indicated that the low-temperature properties had decreased after water foaming. The aggregative state conversion phase of 70\# asphalt and 70\# foamed asphalt had ended before $55^{\circ} \mathrm{C}$, which indicated that the physical properties of asphalt does not change obviously after water foaming and the high-temperature properties of foamed asphalt are similar to that of the base asphalt. The softening point of base asphalt and foamed asphalt is $52.1{ }^{\circ} \mathrm{C}$ and $48.8^{\circ} \mathrm{C}$, respectively. The DSC curves of base asphalt and foamed asphalt have an absorption peak near the softening point temperature. Then, with the increase of temperature, the curve is flat and no obvious absorption peak, which only represents the relationship between viscosity and temperature. The aggregative state conversion temperature range of the base asphalt and foamed asphalt was $-29.77-53.16^{\circ} \mathrm{C}$ and $-15.88-47.38^{\circ} \mathrm{C}$, respectively. After water foaming, the aggregative state conversion temperature of asphalt was reduced, which was consistent with the softening point test results. The TGA curve of foamed asphalt was smoother than the base asphalt, and the TGA curve of foamed asphalt had a relatively less endothermic peak. This might be that the aggregate state of foamed asphalt had no fixed transition temperature range due to the addition of moisture, and in addition, the aggregate state conversion was a gradual process.

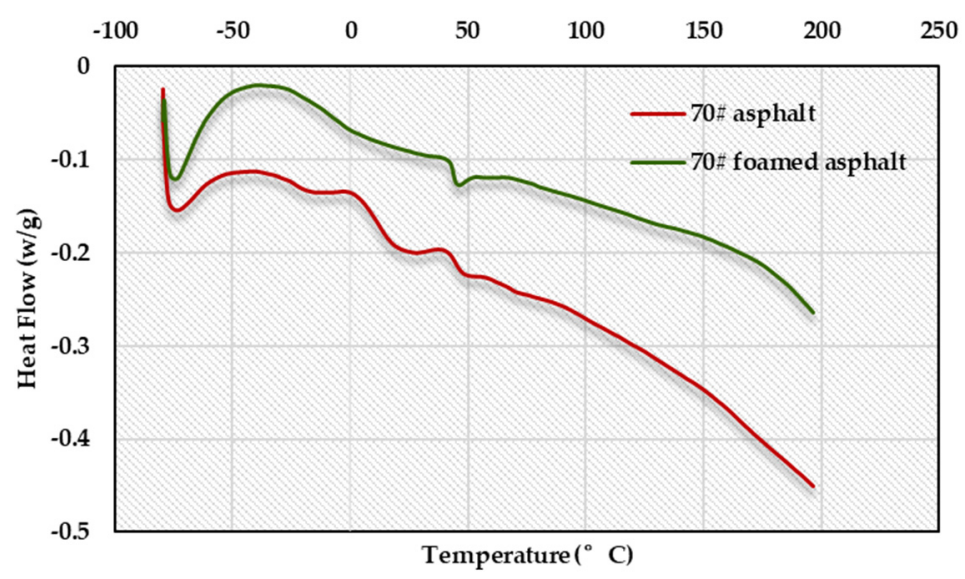

Figure 8. Differential scanning calorimetry (DSC) spectrum of 70\# asphalt and 70\# foamed asphalt.

Four main parameters could be obtained from the DSC curve based on Origin Pro 9.1, including temperature range of endothermic peak, endothermic peak area, total endothermic peak area and endothermic peak height. The endothermic peak data of base asphalt and foamed asphalt are summarized in Table 4. 
Table 4. Main parameters of the DSC curve of the base asphalt and foamed asphalt.

\begin{tabular}{ccccc}
\hline Type & $\begin{array}{c}\text { Temperature Range of } \\
\text { Endothermic Peak } \\
\left({ }^{\circ} \mathbf{C}\right)\end{array}$ & $\begin{array}{c}\text { Endothermic Peak } \\
\text { Area (J/g) }\end{array}$ & $\begin{array}{c}\text { Total Endothermic } \\
\text { Peak Area (J/g) }\end{array}$ & $\begin{array}{c}\text { Endothermic Peak } \\
\text { Height (W/g) }\end{array}$ \\
\hline \multirow{2}{*}{ 70\# asphalt } & -79.70 to -43.96 & 1.48563 & & 0.08808 \\
& -30.65 to -0.51 & 0.15198 & 2.37756 & 0.00897 \\
& 2.99 to 40.64 & 0.63642 & & 0.02955 \\
70\# foamed asphalt & 40.64 to 55.14 & 0.10353 & 0.01197 \\
\hline & -78.86 to 55.25 & 1.33244 & 0.06842 \\
& -55.08 to -12.17 & 0.10639 & 2.49943 & 0.00675 \\
& -11.67 to 38.47 & 0.3763 & 0.01118 \\
\hline
\end{tabular}

From Table 4, it can be seen that the total endothermic peak area of foamed asphalt was higher than that of base asphalt, indicating that the thermal stability of base asphalt decreased after the incorporation of water, which is consistent with the conclusion that the temperature sensitivity of foamed asphalt is poorly derived from the penetration test. Although the moisture incorporated did not react chemically with asphalt, the moisture molecules still had an influence on the internal structure of asphalt physically, which was manifested by the inconsistent DSC curves of the base asphalt and foamed asphalt. The temperature range of the endothermic peak of the base asphalt changed little compared with base asphalt, which demonstrated that the incorporation of moisture still had less effect on the internal colloidal structure of the asphalt.

The DSC curve of foamed asphalt after 30 frozen cycles and $30 \mathrm{~F}-\mathrm{T}$ cycles are shown in Figure 9. It can be known from Figure 9 that the glass transition temperature of foamed asphalt after 30 frozen cycles was $-0.05^{\circ} \mathrm{C}$, which was higher than that of unfrozen foamed asphalt. This indicates that the low-temperature properties of foamed asphalt deteriorated after the low-temperature frozen procedure. After the long-term frozen procedure, the physical properties of foamed asphalt changed significantly, which manifested by the widening of the glass transition temperature range and viscous flow transition temperature range of asphalt after being frozen. After being long-term frozen, the aggregation state transition temperature range was $-0.05^{\circ} \mathrm{C}$ and $101.07^{\circ} \mathrm{C}$, and an endothermic peak emerged in the high temperature zone. This might be because the frozen procedure accelerates the aging of foamed asphalt, making foamed asphalt harder and requiring more heat to transfer state, so the high-temperature stability of frozen foamed asphalt is better than that of foamed asphalt. As shown in Figure 9, the heat absorption of foamed asphalt was significantly increased after $30 \mathrm{~F}-\mathrm{T}$ cycles, indicating that foamed asphalt with $\mathrm{F}-\mathrm{T}$ cycles requires more energy during the aggregate state transition process.

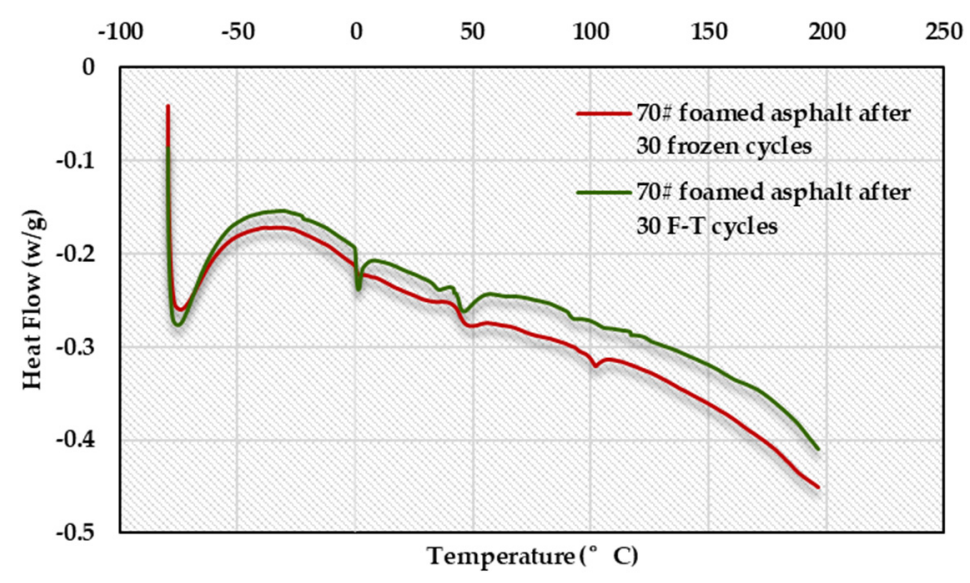

Figure 9. DSC spectrum of foamed asphalt after 30 frozen cycles and 30 F-T cycles. 
The endothermic peak data of foamed asphalt with 30 frozen cycles and foamed asphalt with $30 \mathrm{~F}-\mathrm{T}$ cycles are summarized in Table 5 . After a long-term frozen procedure, the aggregation state transition interval was widened. It can be seen from the temperature range of the endothermic peak index of Tables 4 and 5, the temperature range of the whole endothermic peak of unfrozen foamed asphalt and foamed asphalt with 30 frozen cycles was $-78.86432-52.1278^{\circ} \mathrm{C}$ and $-79.65875-107.1518^{\circ} \mathrm{C}$, respectively. This indicated that the composition of the micelles of asphalt colloid structure had changed. The long-term frozen procedure transformed the foamed asphalt from viscoelasticity to elasticity, which made the foamed asphalt exhibit gel properties. The temperature range of whole endothermic peak foamed asphalt with $30 \mathrm{~F}-\mathrm{T}$ cycles was $-79.7153-162.5536^{\circ} \mathrm{C}$, and the total endothermic peak area was $1.6673 \mathrm{~J} / \mathrm{g}$. It can be concluded that the total endothermic peak area was reduced after $\mathrm{F}-\mathrm{T}$ cycles, and the reduction of F-T cycles procedure was lower than that of the frozen procedure, which indicated that the $\mathrm{F}-\mathrm{T}$ cycle procedure had the most significant influence on thermal properties of foamed asphalt.

Table 5. The endothermic peak data of foamed asphalt with 30 frozen cycles and foamed asphalt with 30 F-T cycles.

\begin{tabular}{ccccc}
\hline Type & $\begin{array}{c}\text { Temperature Range of } \\
\text { Endothermic Peak }\left({ }^{\circ} \mathbf{C}\right)\end{array}$ & $\begin{array}{c}\text { Endothermic Peak } \\
\text { Area (J/g) }\end{array}$ & $\begin{array}{c}\text { Total Endothermic } \\
\text { Peak Area (J/g) }\end{array}$ & $\begin{array}{c}\text { Endothermic Peak } \\
\text { Height (W/g) }\end{array}$ \\
\hline & -79.65875 to -57.6721 & 1.63173 & & 0.12816 \\
& -32.59482 to -29.9332 & 0.00347 & & 0.00199 \\
70\# foamed asphalt & -0.47786 to 8.18376 & 0.03445 & & 0.0077 \\
after 30 frozen & 9.68267 to 38.33634 & 0.11853 & 2.00626 & 0.00634 \\
cycles & 40.83532 to 56.49773 & 0.12502 & & 0.01459 \\
& 66.1653 to 80.3256 & 0.01904 & 0.00193 \\
& 92.98804 to 95.487 & 0.00523 & 0.0032 \\
& 95.487 to 107.1518 & 0.06879 & 0.01279 \\
\hline & -79.7153 to -60.41152 & 1.38191 & & 0.12271 \\
70\# foamed asphalt & -22.5309 to -21.36566 & 0.00151 & & 0.00174 \\
& -0.89164 to 6.76853 & 0.12488 & & 0.04287 \\
& 32.91625 to 40.74777 & 0.02455 & 0.00553 \\
& 43.24372 to 53.74433 & 0.09458 & 1.66730 & 0.01608 \\
& 90.5688 to 95.40174 & 0.01212 & & 0.00362 \\
& 102.732 to 112.0659 & 0.01645 & & 0.00284 \\
& 116.7311 to 119.3974 & 0.00503 & & 0.00304 \\
& 156.556 to 162.5536 & 0.00627 & & 0.00126 \\
\hline
\end{tabular}

\subsection{Rheological Properties}

\subsubsection{Temperature Sweep Test Results}

Temperature sweep test results of foamed asphalt and foamed asphalt with $30 \mathrm{~F}-\mathrm{T}$ cycles are summarized in Table 6.

Table 6. Temperature sweep test results of foamed asphalt and foamed asphalt with $30 \mathrm{~F}-\mathrm{T}$ cycles.

\begin{tabular}{|c|c|c|c|c|c|c|}
\hline Type & Temperature $\left({ }^{\circ} \mathrm{C}\right)$ & $\delta\left({ }^{\circ}\right)$ & $G^{*}(p a)$ & $G^{\prime}($ pa) & $\mathrm{G}^{*} \sin \delta(\mathrm{pa})$ & $\mathrm{G}^{*} / \sin \delta(\mathrm{pa})$ \\
\hline \multirow{5}{*}{$\begin{array}{c}\text { Foamed } \\
\text { asphalt }\end{array}$} & 52 & 82.75 & 8826 & 1113 & 8756 & 8897 \\
\hline & 58 & 86.49 & 3553 & 403 & 3530 & 3576 \\
\hline & 64 & 83.64 & 1600 & 117.3 & 1590 & 1610 \\
\hline & 70 & 82.65 & 789.2 & 101 & 782.8 & 795.8 \\
\hline & 76 & 83.09 & 419.3 & 50.46 & 416.3 & 422.4 \\
\hline \multirow{5}{*}{$\begin{array}{c}\text { Foamed } \\
\text { asphalt after } \\
30 \text { F-T cycles }\end{array}$} & 52 & 83.04 & 10912 & 1322 & 10831 & 10993 \\
\hline & 58 & 83.67 & 4684 & 516 & 4655 & 4712 \\
\hline & 64 & 84.78 & 2070 & 188 & 2062 & 2078 \\
\hline & 70 & 85.01 & 1094 & 95 & 1089 & 1098 \\
\hline & 76 & 84.58 & 527.8 & 49 & 525.4 & 530.2 \\
\hline
\end{tabular}


It can be seen from Table 6 that the rutting factor of asphalt sample decreased with the increase of temperature. Moreover, the rutting factor of foamed asphalt after $30 \mathrm{~F}-\mathrm{T}$ cycles was $23.6-38.1 \%$ higher than that of the foamed asphalt during the test temperature range. This indicates that the foamed asphalt will become hard and its fluidity will be reduced after repeated F-T cycles, thereby the properties of permanent deformation resistance at a high temperature were improved, and the rutting resistance performance was enhanced. Loss shear modulus (viscosity modulus, $G^{\prime \prime}=G^{*} \sin \delta$ ) is the force required for the viscous deformation of asphalt during flowing. As seen, it can be found that the loss shear modulus of two foamed asphalt samples decreased with the increase of temperature. This indicates that the higher the temperature, the smaller the energy lost by the internal friction of asphalt during deformation, and the slower the energy loss rate under repeated load, the stronger the fatigue resistance. The loss shear modulus of the foamed asphalt after $30 \mathrm{~F}-\mathrm{T}$ cycles was higher than that of foamed asphalt, indicating that the energy loss of foamed asphalt after $30 \mathrm{~F}-\mathrm{T}$ cycles was faster than that of foamed asphalt, and the fatigue resistance of foamed asphalt after F-T cycles was poor. The storage shear modulus (elastic modulus, $G^{\prime}=G^{*} \cos \delta$ ), which reflects the storage and release of energy during the deformation of asphalt. The structure of the foamed asphalt after F-T cycles was changed, causing the flow properties of foamed asphalt after F-T cycles different from foamed asphalt at different temperatures. It can be seen from Table 6 that the storage modulus of both asphalt samples decreased with increasing temperature, and the storage modulus of foamed asphalt after F-T cycles decreased more than that of foamed asphalt. The storage modulus of foamed asphalt and foamed asphalt after F-T cycles was 8759 pa and 10,831 pa, respectively, at $52{ }^{\circ} \mathrm{C}$. When the temperature rose to $76^{\circ} \mathrm{C}$, the storage modulus of foamed asphalt and foamed asphalt after F-T cycles was 50.46 pa and $49.85 \mathrm{pa}$, respectively. This indicates that the storage modulus of foamed asphalt after F-T cycles was very close to the storage modulus of foamed asphalt at high temperature and the foamed asphalt after F-T cycles had the same recovery ability as foamed asphalt under high temperature and low frequency.

\subsubsection{Frequency Sweep Test Results}

The phase angle of foamed asphalt and foamed asphalt with $30 \mathrm{~F}-\mathrm{T}$ cycles in the frequency range of $0.1-100 \mathrm{rad} / \mathrm{s}$ is shown in Figure 10.

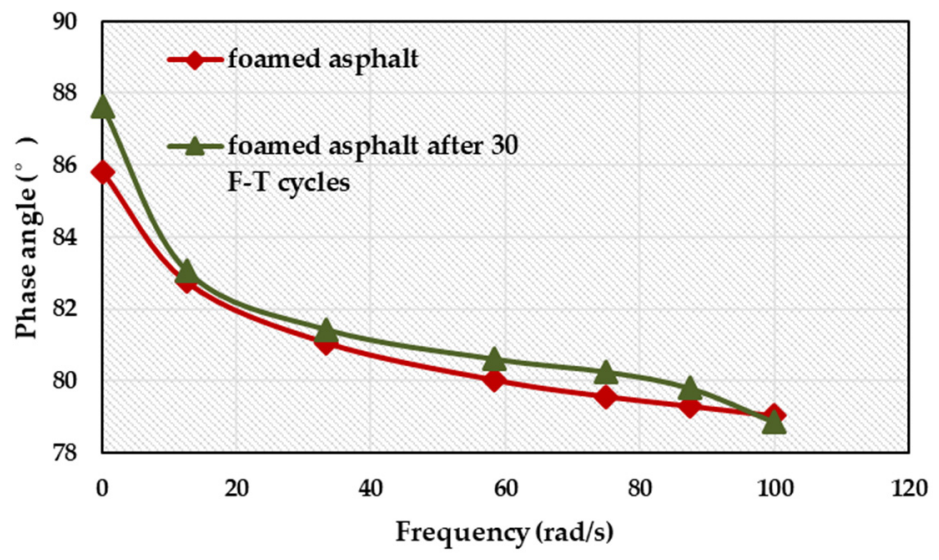

Figure 10. Phase angle of foamed asphalt and foamed asphalt with $30 \mathrm{~F}-\mathrm{T}$ cycles.

The dynamic loading stress is mainly produced on the pavement by vehicles. The asphalt material also shows different viscoelasticity under different frequency loads. It can be seen from Figure 10 that the phase angle of two asphalt samples decreased with the increase of frequency, and the mechanical response of two asphalt samples was closer to the elastic behavior. This is because the increase of frequency causes the proportion of the elastic deformation of the asphalt, so the phase angle of asphalt samples decreased with increasing frequency. The phase angle trend of foamed asphalt after F-T cycles was similar to that of foamed asphalt. After F-T cycles, the phase angle of foamed asphalt was not 
stable in the frequency range of $0.1-100 \mathrm{rad} / \mathrm{s}$, indicating that the internal structure of foamed asphalt was not a homogeneous continuous phase.

The complex shear modulus of foamed asphalt and foamed asphalt with $30 \mathrm{~F}-\mathrm{T}$ cycles in the frequency range of 0.1-100 rad/s is shown in Figure 11.

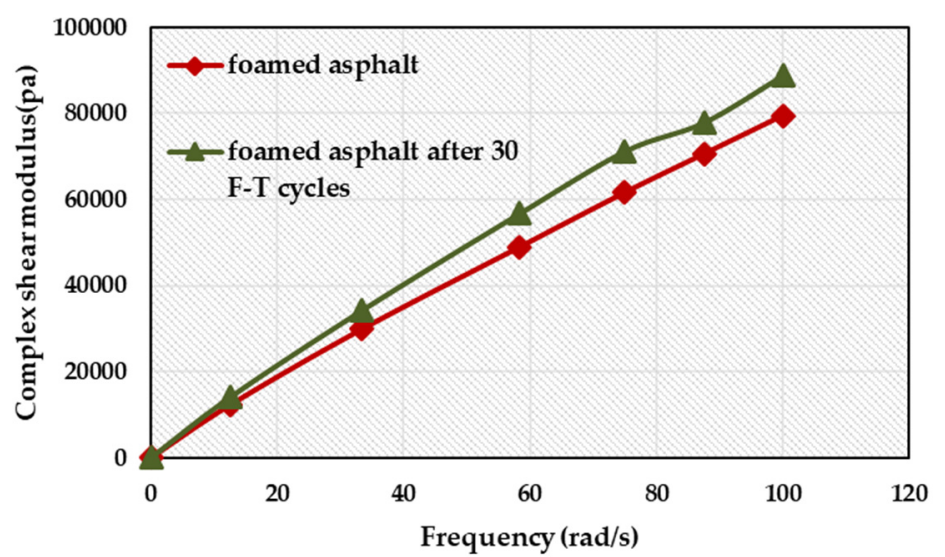

Figure 11. Complex shear modulus of foamed asphalt and foamed asphalt with $30 \mathrm{~F}-\mathrm{T}$ cycles.

It can be seen from Figure 11 that the complex modulus $\mathrm{G}^{*}$ of two asphalt samples increased with the increase of frequency. This is because the time of external stress acting on asphalt mortar becomes shorter with the increase of frequency, which reduces the strain of asphalt material and increases the complex modulus. The phase angle and complex modulus of asphalt samples had an opposite trend with increasing frequency. This is because the elastic deformation component increased with increasing frequency during the load cycle. The sensitivity of the complex modulus of asphalt samples to frequency is characterized by the slope of the linear regression line. The results show that the slope of foamed asphalt after F-T cycles was larger than the foamed asphalt, which indicates that the foamed asphalt after the F-T cycle had higher sensitivity to frequency and it had poor temperature sensitivity.

The storage modulus of foamed asphalt and foamed asphalt with $30 \mathrm{~F}-\mathrm{T}$ cycles in the frequency range of $0.1-100 \mathrm{rad} / \mathrm{s}$ is shown in Figure 12.

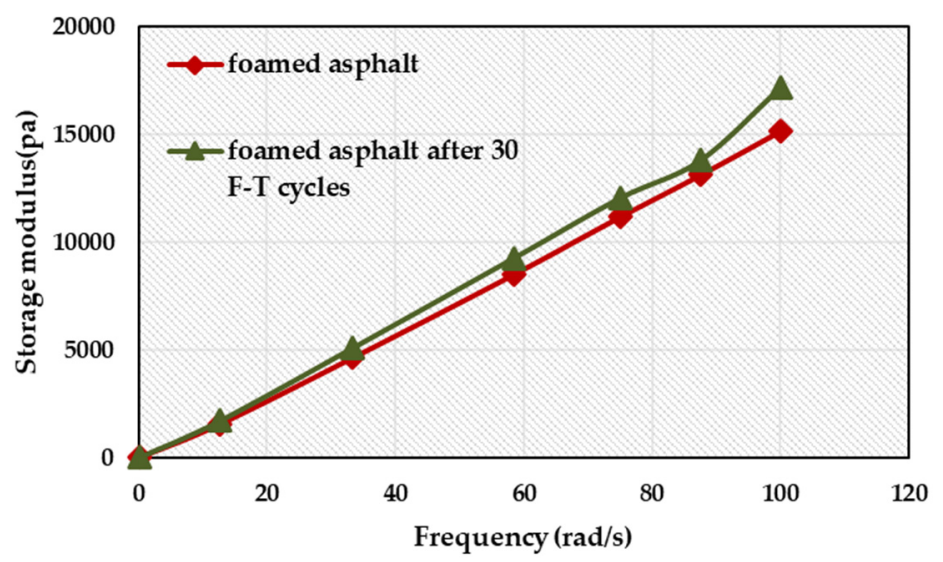

Figure 12. Storage modulus of foamed asphalt and foamed asphalt with $30 \mathrm{~F}-\mathrm{T}$ cycles.

It can be seen from Figure 12 that the storage modulus of two asphalt samples increased with the increase of frequency. When the frequency of pavement was $100 \mathrm{rad} / \mathrm{s}$, the storage modulus of foamed asphalt and foamed asphalt after F-T cycles were 15140 pa and $17151 \mathrm{pa}$, respectively. The storage modulus of foamed asphalt increased after F-T cycles, and the increase was $13.3 \%$. This is because the foamed asphalt after F-T cycles became harder, and the complex modulus increased, but the phase 
angle change was relatively small. Thereby, the storage modulus of foamed asphalt after the F-T cycle was increased and the restoration of deformation ability was improved.

\subsection{Microscopic Properties}

The microstructure of asphalt samples was examined by a SIGMA 300 scanning electron microscope. The scanning electron micrographs of base asphalt and foamed asphalt before and after F-T cycles observed at a magnifying power of $\times 5000$ are shown in Figure 13a-d.

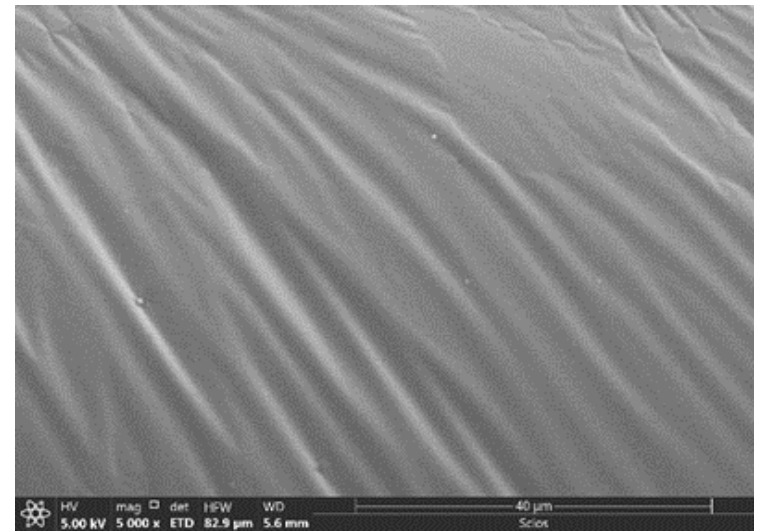

(a)

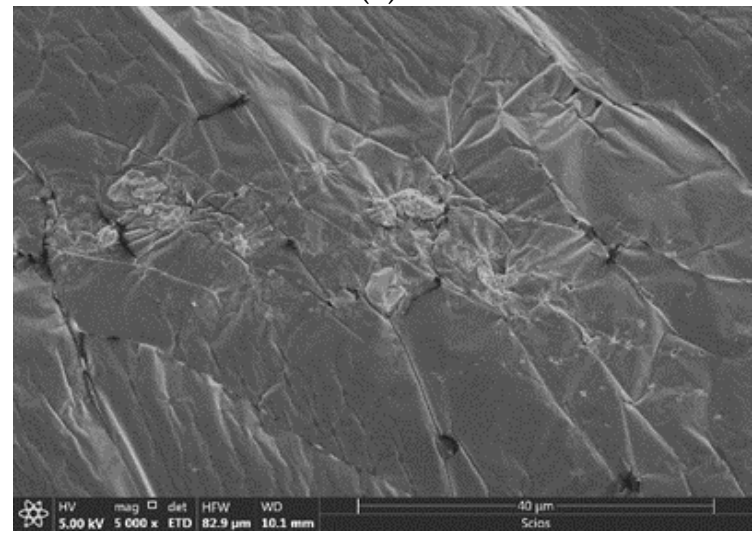

(c)

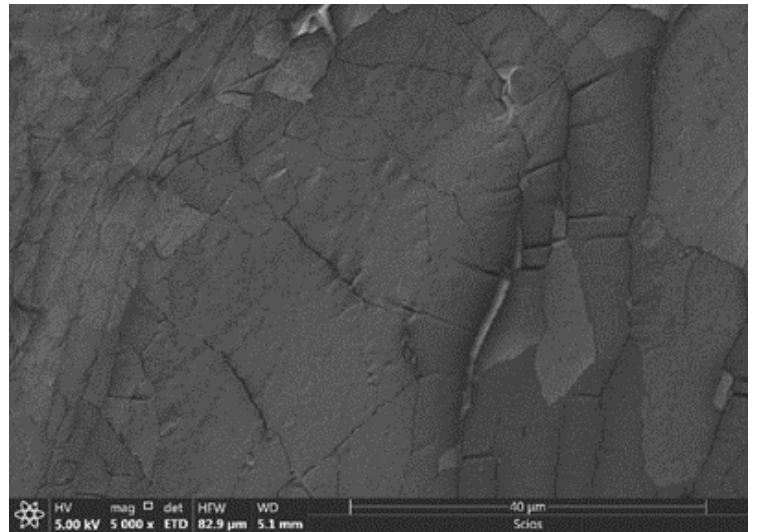

(b)

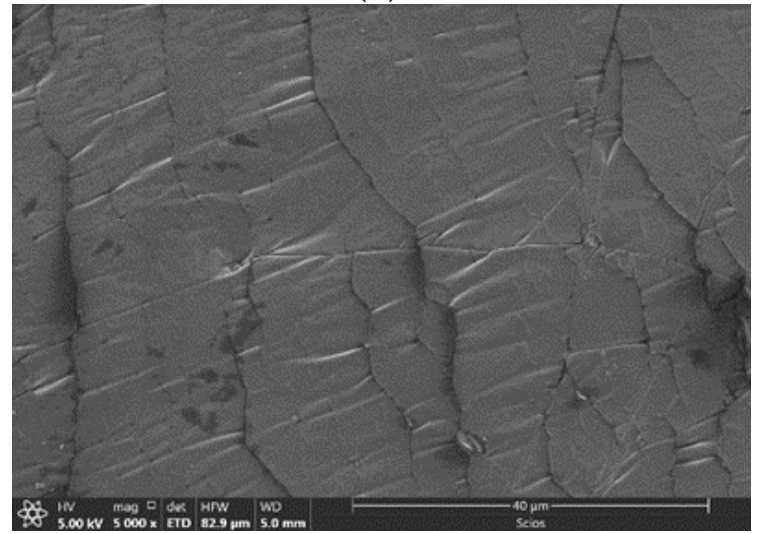

(d)

Figure 13. SEM images of base asphalt and foamed asphalt before and after F-T cycles at magnifications of $\times 5000$. (a) 70\# asphalt; (b) 70\# asphalt after F-T cycles; (c) 70\# foamed asphalt and (d) 70\# foamed asphalt after F-T cycles.

It can be seen from Figure 13 that the surface of base asphalt was relatively flat, had more texture structure and exhibited a homogeneous phase substance. After F-T cycles, the crack occurred on the surface of base asphalt. As the number of F-T cycles increased, the cracks evolved into a network of wrinkled lines. This might be due to the temperature stress that was generated on the surface of asphalt under repeated action of temperature and moisture, which makes the structure of asphalt membrane break and the surface appears fragmented block. Moreover, asphalt will become brittle and hard under the action of $\mathrm{F}-\mathrm{T}$ cycle, which also aggravates the cracking phenomenon of asphalt.

Compared with the base asphalt, the internal moisture of foamed asphalt was fully integrated with asphalt, so that the circular "cavitation" emerged on the asphalt surface and asphalt was in a fluffy state. This microstructure played an "isolation" role in the asphalt, reducing the overall viscosity of moisture-asphalt mixes and the engineering mixing temperature. After F-T cycles, the circular "cavitation" gradually disappeared, and the microscopic morphology was similar to that of base asphalt after F-T cycles. This may be because the internal moisture was gradually precipitated under 
the action of temperature and moisture capillary force. In addition, the self-healing ability of asphalt aggravated the disappearance of the circular "cavitation" structure.

\section{Conclusions}

In this study, the properties of water-foamed asphalt under three different environments were characterized through conventional physical properties tests, DSR test, DSC test and SEM test for a better understanding of the workability of water-foamed asphalt under different environments. The conventional physical properties tests were employed to characterize the deterioration of water-foamed asphalt under different environmental factors and determine the most significant environmental factors for foamed asphalt. The DSR test was conducted to assess the high-temperature stability and fatigue resistance of treated foamed asphalt. The DSC test was conducted to evaluate thermal properties of water-foamed asphalt under the most adverse environmental factor. The SEM test was employed for microscopic observation of water-foamed asphalt samples. Based on these experiments, several conclusions could be drawn:

- Conventional physical properties test results showed that the performance of the foamed binder had declined under three environmental processes. With the increase of process time, the softening point and viscosity of foamed asphalt increased, and the penetration and ductility decreased. Moreover, the foamed asphalt gradually returned to the characteristics before being foamed, with the increase of process time.

- A comprehensive evaluation index, deterioration degree was proposed based on the conventional physical properties test results and entropy theory, and the deterioration process of foamed binder under three environmental conditions was quantified. The F-T cycles have been proved to have the most significant influence on the performance of foamed binder among three environmental factors, which is a key issue that limits the application and promotion of foamed asphalt in seasonal frozen regions.

- DSR test showed that the rutting factor of foamed asphalt had been increased by $23.6-38.1 \%$ after F-T cycles, which indicated that the resistance to high-temperature permanent deformation of foamed binder was improved after F-T cycles. The loss modulus of foamed binder increased after F-T cycles, and the fatigue resistance became worse.

- Storage modulus results indicated that the recovery ability of the foamed asphalt after F-T cycles was similar to original foamed asphalt under high temperature and low frequency conditions, and the foamed asphalt had a stronger deformation recovery ability after F-T cycles under a moderate temperature and high frequency condition. The sensitivity analysis of a complex modulus to frequency showed that foamed asphalt after F-T cycles was more sensitive to the loading frequency and less sensitive to the temperature.

- The glass transition temperature of base asphalt and foamed asphalt was $-29.77^{\circ} \mathrm{C}$ and $-15.88^{\circ} \mathrm{C}$, respectively, indicating that the low-temperature properties of asphalt decreased after foaming. The aggregate transition temperature of both asphalt samples was less than $55^{\circ} \mathrm{C}$, which proved the foaming process of a binder was a physical phenomenon. The endothermic peak data of DSC curves showed that the reduced total endothermic peak area caused by the F-T cycles was greater than that caused by frozen process, and the foamed asphalt after the F-T cycles had a wider endothermic temperature range than foamed asphalt after the frozen process. This indicated the F-T cycles had the most serious impact on foamed asphalt, which is also consistent with the conventional physical properties test results.

- SEM test demonstrated that the circular "cavitation" emerged on the asphalt surface and asphalt was in a fluffy state after foaming. This microstructure played an "isolation" role in the asphalt, reducing the overall viscosity of the engineering mixing temperature. After F-T cycles, the circular "cavitation" gradually disappeared, and the microscopic morphology was similar to that of base 
asphalt after F-T cycles. This indicated that the moisture of foamed asphalt was gradually precipitated and the self-healing phenomenon occurred during F-T cycles.

Author Contributions: Data curation, W.G. and Y.L.; Formal analysis, W.G.; Funding acquisition, X.G.; Investigation, W.G. and X.G.; Project administration, X.G.; Resources, X.G. and W.D.; Software, W.G.; Writing-original draft, W.G. and Y.L.; Writing—review and editing, W.D. All authors have read and agreed to the published version of the manuscript.

Funding: This research was funded by the National Nature Science Foundation of China (NSFC) (Grant No. 51178204) and Jilin Province Science and Technology Development Plan Project (20190303033SF).

Conflicts of Interest: The authors declare that there is no conflict of interests regarding the publication of this paper.

\section{References}

1. Guo, W.; Guo, X.D.; Chen, X. Aggregate-Bitumen Interface Enhancement Mechanism of Utilization of Oil shale Waste as Fine Aggregate in Open Grade Friction Course. Coatings 2019, 9, 637. [CrossRef]

2. Yu, J.; Ren, Z.; Gao, Z. Recycled Heavy Bio Oil as Performance Enhancer for Rubberized Bituminous Binders. Polymers 2019, 11, 800. [CrossRef] [PubMed]

3. Pasetto, M.; Baldo, N. Unified approach to fatigue study of high performance recycled asphalt concretes. Mater. Struct. 2017, 50, 113. [CrossRef]

4. Karnati, S.R.; Oldham, D.; Fini, E.H.; Zhang, L.F. Surface functionalization of silica nanoparticles to enhance aging resistance of asphalt binder. Constr. Build. Mater. 2019, 211, 1065-1072. [CrossRef]

5. Mousavi, M.; Pahlavan, F.; Oldham, D. Multiscale investigation of oxidative aging in biomodified asphalt binder. J. Phys. Chem. C. 2016, 120, 17224-17233. [CrossRef]

6. Li, Z.G.; Hao, P.W.; Liu, H.Y. Investigation of early-stage strength for cold recycled asphalt mixture using foamed asphalt. Constr. Build. Mater. 2016, 127, 410-417. [CrossRef]

7. Hailesilassie, B.W.; Hugener, M.; Partl, M.N. Influence of foaming water content on foam asphalt mixtures. Constr. Build. Mater. 2015, 85, 65-77. [CrossRef]

8. Ozturk, H.I.; Kutay, M.E. Novel Testing Procedure for Assessment of Quality of Foamed Warm Mix Asphalt Binders. J. Mater. Civil. Eng. 2014, 26, 04014042. [CrossRef]

9. Wen, H.F.; Lu, J.; VanReken, T.M. Modeling the Effects on Energy and Carbon Dioxide from the Use of Recycled Asphalt Pavement in Hot Mix Asphalt. Int. J. Sustain. Trans. 2014, 8, 249-261. [CrossRef]

10. Abreu, L.P.P.; Oliveira, J.R.M.; Silva, H.M.R.D. Recycled asphalt mixtures produced with high percentage of different waste materials. Constr. Build. Mater. 2015, 8, 230-238. [CrossRef]

11. Lwanski, M.; Chomicz-Kowalska, A.; Maciejewski, K. Application of synthetic wax for improvement of foamed bitumen parameters. Constr. Build. Mater. 2015, 83, 62-69. [CrossRef]

12. Arega, Z.A.; Bhasin, A.; Li, W.; Newcomb, D.E. Characteristics of Asphalt Binders Foamed in the Laboratory to Produce Warm Mix Asphalt. J. Mater. Civil. Eng. 2014, 26, 0414078. [CrossRef]

13. Fang, F.T.; Chong, Y.C.; Nyunt, T.T.; Loi, S.S. Development of environmentally sustainable pavement mix. Int. J. Pavement Res. Technol. 2013, 6, 440-446. [CrossRef]

14. Wang, Y.H.; Wang, G.; Ahn, Y.H. Effects of Using Recycled Asphalt Shingles in Open Graded Friction Course on Flexible Pavement Performance. J. Test. Eval. 2014, 42, 1173-1182. [CrossRef]

15. Guo, W.; Guo, X.D.; Chen, X. Properties Analysis of Oil Shale Waste as Partial Aggregate Replacement in Open Grade Friction Course. Appl. Sci. 2018, 8, 1626. [CrossRef]

16. Santero, N.J.; Masanet, E.; Horvath, A. Life-cycle assessment of pavements. Part I: Critical review. Resour. Conserv. Recycl. 2011, 55, 801-809. [CrossRef]

17. Rubio, M.C.; Martinez, G.; Baena, L. Warm mix asphalt: An overview. J. Clean. Prod. 2012, $24,76-84$. [CrossRef]

18. Jamshidi, A.; Hamzah, M.O.; You, Z.P. Performance of Warm Mix Asphalt containing Sasobit (R): State-oF-The-art. Constr. Build. Mater. 2013, 38, 530-553. [CrossRef]

19. Barigi, B.K.; Mannan, U.A.; Tarefder, R.A. Tribological Approach to Demonstrate Workability of Foamed Warm-Mix Asphalt. J. Mater. Civ. Eng. 2019, 31, 04019191. [CrossRef]

20. Barigi, B.K.; Mannan, U.A.; Tarefder, R.A. Influence of foaming on tribological and rheological characteristics of foamed asphalt. Constr. Build. Mater. 2019, 205, 186-195. [CrossRef] 
21. Capitao, S.D.; Picado-Santos, L.G.; Martinho, F. Pavement engineering materials: Review on the use of warm-mix asphalt. Constr. Build. Mater. 2012, 36, 1016-1024. [CrossRef]

22. Hasan, M.R.M.; You, Z.P. Comparative study of ethanol foamed asphalt binders and mixtures prepared via manual injection and laboratory foaming device. J. Traffic Transp. Eng. 2019, 6, 383-395. [CrossRef]

23. Hou, Y.; Cai, Y.X.; Zang, Z.S. Dynamic Characteristics of Warm Mix Foamed Asphalt Mixture in Seasonal Frozen Area. Adv. Mater. Sci. Eng. 2019, 1825643. [CrossRef]

24. Martinez-Arguelles, G.; Giustozzi, F.; Crispino, M. Laboratory investigation on mechanical performance of cold foamed bitumen mixes: Bitumen source, foaming additive, fiber-reinforcement and cement effect. Constr. Build. Mater. 2015, 93, 241-248. [CrossRef]

25. Kheradmand, B.; Munuandy, R.; Hua, L.T. An overview of the emerging warm mix asphalt technology. Int. J. Pavement Eng. 2014, 15, 79-94. [CrossRef]

26. Ge, D.D.; Yan, K.Z.; You, L.Y. Modification mechanism of asphalt modified with Sasobit and Polyphosphoric acid (PPA). Constr. Build. Mater. 2017, 143, 419-428. [CrossRef]

27. Zhao, S.; Huang, B.S.; Shu, X. Comparative evaluation of warm mix asphalt containing high percentages of reclaimed asphalt pavement. Constr. Build. Mater. 2013, 44, 92-100. [CrossRef]

28. Han, A.; Bahia, H. Asphalt binder contribution to mixture workability and application of asphalt lubricity test to estimate compact ability temperatures for warm-mix asphalt. Transp. Res. Rec. 2013, 2371, 87-95. [CrossRef]

29. Diab, A.; You, Z. Rheological characteristics of nano-sized hydrated lime-modified foamed warm mix asphalt. Pavement Mater. Struct. Perform 2014, 79-89. [CrossRef]

30. You, L.Y.; You, Z.P.; Dai, Q.L. Characteristics of Water-Foamed Asphalt Mixture under Multiple Freeze-Thaw Cycles: Laboratory Evaluation. J. Mater. Civ. Eng. 2018, 30, 04018270. [CrossRef]

31. Hasan, M.R.M.; You, Z.P. Ethanol based foamed asphalt as potential alternative for low emission asphalt technology. J. Traffic Transp. Eng. 2016, 3, 116-126. [CrossRef]

32. Hasan, M.R.M.; You, Z.P.; Porter, D. Laboratory moisture susceptibility evaluation of WMA under possible field conditions. Constr. Build. Mater. 2015, 101, 57-64. [CrossRef]

33. Wielinski, J.; Hand, A.; Rausch, D.M. Laboratory and Field Evaluations of Foamed Warm-Mix Asphalt Projects. Transp. Res. Rec. 2009, 2126, 125-131. [CrossRef]

34. Apeagyei, A.K. Evaluating Foamed Asphalt Stability Using Acoustic Emission Techniques. J. Mater. Civ. Eng. 2013, 25, 1291-1298. [CrossRef]

35. Wahhab, H.I.A.; Baig, M.G.; Mahmoud, I.A. Study of road bases construction in Saudi Arabia using foam asphalt. Constr. Build. Mater. 2012, 26, 113-121. [CrossRef]

36. Hasan, M.R.M.; You, Z.P.; Yang, X. A comprehensive review of theory, development, and implementation of warm mix asphalt using foaming techniques. Constr. Build. Mater. 2017, 152, 115-133. [CrossRef]

37. Arega, Z.A.; Bhasin, A.; Li, W. Parametric Analysis of Factors That Affect Asphalt Binder Foaming Characteristics. J. Mater. Civ. Eng. 2015, 27, 04015052. [CrossRef]

38. Dong, F.Q.; Yu, X.; Wang, T.Y. Influence of base asphalt aging levels on the foaming characteristics and rheological properties of foamed asphalt. Constr. Build. Mater. 2018, 177, 43-50. [CrossRef]

39. Punith, V.S.; Xiao, F.P.; Putman, B. Effects of long-term aging on moisture sensitivity of foamed WMA mixtures containing moist aggregates. Mater. Struct. 2012, 45, 251-264. [CrossRef]

40. Abu Qtaish, L.; Nazzal, M.D.; Abbas, A. Micromechanical and Chemical Characterization of Foamed Warm-Mix Asphalt Aging. J. Mater. Civ. Eng. 2018, 30, 04018213. [CrossRef]

41. Kim, Y.; Lee, H. Development of mix design procedure for cold in-place recycling with foamed asphalt. J. Mater. Civ. Eng. 2006, 18, 116-124. [CrossRef]

42. Yin, F.; Arambula-Mercado, E.; Newcomb, D. Mix design procedure for foamed asphalt mixtures. Road Mater. Pavement Des. 2016, 17, 946-957. [CrossRef]

43. Lwanski, M.; Mazurek, G.; Buczynski, P. Bitumen Foaming Optimisation Process on the Basis of Rheological Properties. Materials. 2018, 11, 10. [CrossRef]

44. Bazzaz, M.; Darabi, M.K.; Little, D.N.; Garg, N. Effect of Evotherm-M1 on Properties of Asphaltic Materials Used at NAPMRC Testing Facility. J. Test. Eval. 2020, 48. [CrossRef]

45. Darabi, M.K.; Huang, C.W.; Bazzaz, M.; Masad, E.A.; Little, D.N. Characterization and validation of the nonlinear viscoelastic-viscoplastic with hardening-relaxation constitutive relationship for asphalt mixtures. Constr. Build. Mater. 2019, 216, 648-660. [CrossRef] 
46. Bazzaz, M.; Darabi, M.K.; Little, D.N.; Garg, N. A Straightforward Procedure to Characterize Nonlinear Viscoelastic Response of Asphalt Concrete at High Temperatures. Transp. Res. Rec. 2018, 28, 481-492. [CrossRef]

47. Bazzaz, M. Experimental and Analytical Procedures to Characterize Mechanical Properties of Asphalt Concrete Materials for Airfield Pavement Applications. Ph.D. Thesis, University of Kansas, Lawrence, KS, USA, 31 December 2018.

48. Guo, W.; Guo, X.D.; Sun, M.Z. Evaluation of the Durability and the Property of an Asphalt Concrete with Nano Hydrophobic Silane Silica in Spring-Thawing Season. Appl. Sci. 2018, 8, 1475. [CrossRef]

49. ASTM Standard Test Method for Penetration of Bituminous Materials; ASTM D5; ASTM: West Conshohocken, PA, USA, 2013.

50. ASTM Standard Test Method for Softening Point of Bitumen (Ring-and-Ball Apparatus); ASTM D36; ASTM: West Conshohocken, PA, USA, 2013.

51. ASTM Standard Test Method for Ductility of Asphalt Materials; ASTM D113; ASTM: West Conshohocken, PA, USA, 2017.

52. Guo, W.; Guo, X.D.; Chang, M.Y. Evaluating the Effect of Hydrophobic Nanosilica on the Viscoelasticity Property of Asphalt and Asphalt Mixture. Materials 2018, 11, 2328. [CrossRef]

(C) 2020 by the authors. Licensee MDPI, Basel, Switzerland. This article is an open access article distributed under the terms and conditions of the Creative Commons Attribution (CC BY) license (http://creativecommons.org/licenses/by/4.0/). 